Cancer Quality of Life Questionnaire-Core 30 [EORTC QLQ-C30] and Endometrial Cancer Module [EORTC QLQEN24]). Enrolment began December 2020 and is ongoing at 221 sites in 28 countries.

Result(s)* N/A

Conclusion* N/A

\section{LAPAROSCOPIC REPAIR OF OBTURATOR NERVE INJURY AT THE TIME OF PELVIC LYMPHADENECTOMY}

R Linder*, J Gomez, T Feigenberg. trillium health partners, Gynecological Oncology , Canada

10.1136/ijgc-2021-ESG0.124

Introduction/Background* The obturator nerve is formed by the lumbar plexus, receiving its fibers from the anterior division of L2-4. Clinically, obturator nerve injury manifests with sensorial loss at the medial aspect of thigh, pain at medial portion of the groin and ipsilateral adductor weakness. The risk of obturator nerve injury is increased during pelvic lymphadenectomy and surgeries for gynecologic malignancies. Here, we present a video film of full-thickness transection of obturator nerve at the time of pelvic lymphadenectomy in a patient who underwent laparoscopic surgery for endometrial cancer. The transected nerve was primarily repaired through a laparoscopic approach at the time of surgery. The patient experienced a full recovery with no motor function deficiencies

Methodology

Result(s)* In this surgical film we present an 83-year-old woman, G2P2, who was diagnosed with a grade 3 endometrioid endometrial adenocarcinoma. She underwent a laparoscopic hysterectomy and sentinel lymph-node biopsies as well as resection of enlarged external iliac node. During the procedure, we identified a complete transection of the obturator nerve. To enable an end to end repair, the external iliac artery and vein were mobilized. The proximal end of the nerve was identified lateral to these vessels. An end-to-end anastomosis of the nerve was performed using Prolene sutures. The patient experienced an uneventful post-operative recovery and was discharge home on post-operative day 2, able to ambulate independently with no assistance required.

Conclusion* Obturator nerve injuries are a well-recognized complication of pelvic lymphadenectomy. Immediate laparoscopic nerve repair, can facilitate earlier motor recovery and prevent the need for laparotomy.

\section{UTILITY OF PELVIC MRI AND TUMOR MARKERS HE4 AND CA125 TO PREDICT DEPTH OF MYOMETRIAL INVASION AND CERVICAL INVOLVEMENT IN ENDOMETRIAL CANCER}

${ }^{1} \mathrm{~N}$ Zamani*, ${ }^{1} \mathrm{M}$ Modares, ${ }^{2} \mathrm{~F}$ Zamani. ${ }^{1}$ Tehran University of Medical Sciences, gynecologic oncology, Tehran, Iran; ${ }^{2}$ Tehran University of Medical Sciences, radiology, Tehran, Iran

\subsection{6/ijgc-2021-ESGO.125}

Introduction/Background* The purpose of this pilot study was to determine whether the MRI and biomarkers human epididymis protein 4 (HE4) and CA125 correlate with depth of myometrial invasion, histologic grade, cervical involvement and nodal metastases in patients with endometrioid adenocarcinoma of the uterus.

Methodology This was a prospective, observational study in women with biopsy-proven endometrial adenocarcinoma of the uterus. Preoperative pelvic MRI was performed and concentration of HE4 and CA125 were assessed before surgery. All surgical specimens were reviewed by a single expert

Abstract 198 Table 1 Relation between serum CA125 level, serum (HE4) level and histopathological prognostic factors

\begin{tabular}{|c|c|c|c|c|c|c|}
\hline & $\begin{array}{l}\text { HE4 < } \\
140 P M[n \\
(\%)]\end{array}$ & $\begin{array}{l}\text { HE4 } \geq \\
140 P M[n \\
(\%)]\end{array}$ & $p$ & $\begin{array}{l}\text { CA125< } \\
35 \mathrm{ku} / \mathrm{I}[\mathrm{n} \\
(\%)]\end{array}$ & $\begin{array}{l}\text { CA125 } \geq \\
35 \mathrm{ku} / \mathrm{I}[\mathrm{n} \\
(\%)]\end{array}$ & $\mathrm{p}$ \\
\hline FIGO & & & 0.003 & & & 0.002 \\
\hline I & 47 (90.4\%) & $5(9.6 \%)$ & & $38(73.1 \%)$ & $14(26.9 \%)$ & \\
\hline II & $6(66.7 \%)$ & $3(33.3 \%)$ & & $3(33.3 \%)$ & $6(66.7 \%)$ & \\
\hline III & $3(42.9 \%)$ & $4(57.1 \%)$ & & $1(14.3 \%)$ & $6(85.7 \%)$ & \\
\hline $\begin{array}{l}\text { Myometrial } \\
\text { invasion }\end{array}$ & & & 0.001 & & & 0.0001 \\
\hline No & $1(100 \%)$ & $0(0)$ & & $1(100 \%)$ & $0(0)$ & \\
\hline$<50 \%$ & 37 (97.4\%) & $1(2.6 \%)$ & & 32 (84.3\%) & $6(15.7 \%)$ & \\
\hline$\geq 50 \%$ & 18 (62.1\%) & 11 (37.9\%) & & $9(14.3 \%)$ & $6(68.9 \%)$ & \\
\hline Grade & & & 0.035 & & & 0.001 \\
\hline I & 27 (96.5\%) & $1(3.5 \%)$ & & $23(82.2 \%)$ & $5(17.8 \%)$ & \\
\hline II & 25 (71.5\%) & $10(28.5 \%)$ & & 19 (31.1\%) & 16 (45.7\%) & \\
\hline III & $4(80 \%)$ & $1(20 \%)$ & & $0(0)$ & $5(100 \%)$ & \\
\hline $\begin{array}{l}\text { Node } \\
\text { involvement }\end{array}$ & & & 0.007 & & & 0.002 \\
\hline No & $54(85.2 \%)$ & $8(14.8 \%)$ & & $42(66.7 \%)$ & $20(33.3 \%)$ & \\
\hline Yes & $2(33.4 \%)$ & $4(66.6 \%)$ & & $0(0)$ & $6(100 \%)$ & \\
\hline $\begin{array}{l}\text { Cervical } \\
\text { stromal } \\
\text { Involvement }\end{array}$ & & & & & & 0.006 \\
\hline No & 48 (88.9\%) & $6(11.1 \%)$ & & $38(70.4 \%)$ & $16(29.6 \%)$ & \\
\hline Yes & $8(57.2 \%)$ & $6(42.8 \%)$ & & $4(28.6 \%)$ & $10(71.4 \%)$ & \\
\hline
\end{tabular}

